\title{
National Development Plan as an Entrepreneurial Mechanism for Rural Economic Development in
} South Africa

\author{
Elvin Shava*, Tafadzwa Clementine Maramura \\ North West University, South Africa \\ *ellyshava@gmail.com,tmaramura@gmail.com
}

\begin{abstract}
Chapter 6 of the National Development Plan (NDP) accentuates on the impact of an integrated and inclusive rural economy by proposing for the creation 643000 direct jobs and 326000 indirect jobs in the farming and non-farming sector by 2030. Discussion within the study reveals that, the NDP was also designed to stimulate rural economic development among other important dynamic economic factors of the country. However, five years into the implementation of the NDP, remnants of inequality, unemployment and poverty are still apparent amongst the rural population. This paper indicates that the success of NDP as an entrepreneurial mechanism is being underpinned by contestations which are emanating from underfinancing, lack of entrepreneurial education and research culture, negative attitudes of the people, corruption and red tape. Through a qualitative research approach, the paper observes that, for NDP to be continuously coordinated as an economic initiative, financing of rural projects such as small businesses, cooperatives and other rural development projects should be the government's key priority. The study concludes that entrepreneurship has to be considered as a prime mover in rural economic development in South Africa since an entrepreneurial economy significantly differs from a non-entrepreneurial one, as evidenced by the economic vigour and sustainable development of its inhabitants.
\end{abstract}

Keywords: National Development Plan, Entrepreneurship, Rural Economic Development, Poverty Alleviation, Empowerment

\section{Introduction}

"No political democracy can survive and flourish if the mass of our people remain in poverty, without land, without tangible prospects for a better life. Attacking poverty and deprivation must therefore be the first priority of a democratic government." (The Reconstruction and Development Programme, 1994)

Following the infamous improvements made by the previous economic policies (Growth Employment \& Redistribution (GEAR) and Reconstruction and Development Programme (RDP) (Asgisa, 2006), the South African government, in its launching of the National Development Plan 2011-2030, was aware of the challenges which may affect the successful implementation of the economic policy to regenerate employment and stimulate rural economic development. Unfortunately, the remnants of inequality and poverty, more than two decades into a democratic South Africa are still apparent. However, the aim of the National Development Plan (NDP) as adopted by the South African Government in 2012 is to eradicate poverty and decrease inequity by the year 2030 (National Planning Commission (NPC), 2012). South African Government Information (2012) advises that, the government of South Africa can only be able to comprehend the objectives of the NDP by harnessing the energies of the citizens in developing an all-encompassing entrepreneurial mechanism for rural economic development. This is against the background in which fragments of the pre-1994 era have constantly been determining the life opportunities for the cosmic mainstream rural inhabitants in South Africa (Hendriks, 2013). It is vital to note that, these colossal contestations underpinning rural economic development can only be addressed through a paradigmatic shift in the country's entrepreneurial performance.

Audretsch (2007) emphasises that entrepreneurship can either be defined from the innovation perspective or from the risk-taking perspective. Consequently, Petrin (1992) defines an entrepreneur as an individual who produces original permutations of production factors or as an individual who is eager to exploit market opportunities by disregarding market volatility. Ultimately, Young and Sexton (1997) affirm that, the entrepreneurial perspective to rural development assents that entrepreneurship is the keystone of economic growth whose absence leads to the dissolution of the other factors of production. When outlining entrepreneurship from a rural economic development perspective, the presence of an entrepreneurial environment conducive to sustain a healthy economy is a key factor (Wilken, 1979). Rural entrepreneurship 
is, therefore, gaining momentum as a force of economic change that must be present if the NDP is to reach its target in attaining an inclusive rural economy by 2030. Given this background, the significance of this paper lies in its essence to highlight the relationship between entrepreneurship and rural economic development and how the NDP, as a strategic tool, can be redirected as an entrepreneurial mechanism for accelerating rural economic development.

\section{Literature Review}

Characteristics of Rural Entrepreneurship: Over 15 million South Africans rely on social grants, and these grants play a significant role in alleviating poverty (South African Government Information, 2012); however, these grants are insufficient to completely lift people out of poverty. In addition, grant receivers are most vulnerable to commodity price increases since they lack the buying control to escape poverty (NPC, 2011). In these dynamics, low-income households, under-resourced farmers and previously deprived groups become exposed to poverty and inequality (Stats SA, 2012b). While the NDP emphasises on addressing rural economic development through job creation, not much progress is actually evident although entrepreneurship is the most effective strategy to sustainable rural livelihoods (Hendriks, 2013). This implies that there are certain factors that have to be present to ensure successful implementation of any entrepreneurial mechanism in achieving the mandates of the NDP by 2030. Petrin (1992) notes that entrepreneurship, as a rural economic development mechanism, demands an enabling environment in order to flourish as illustrated by the diagrammatic explanation below.

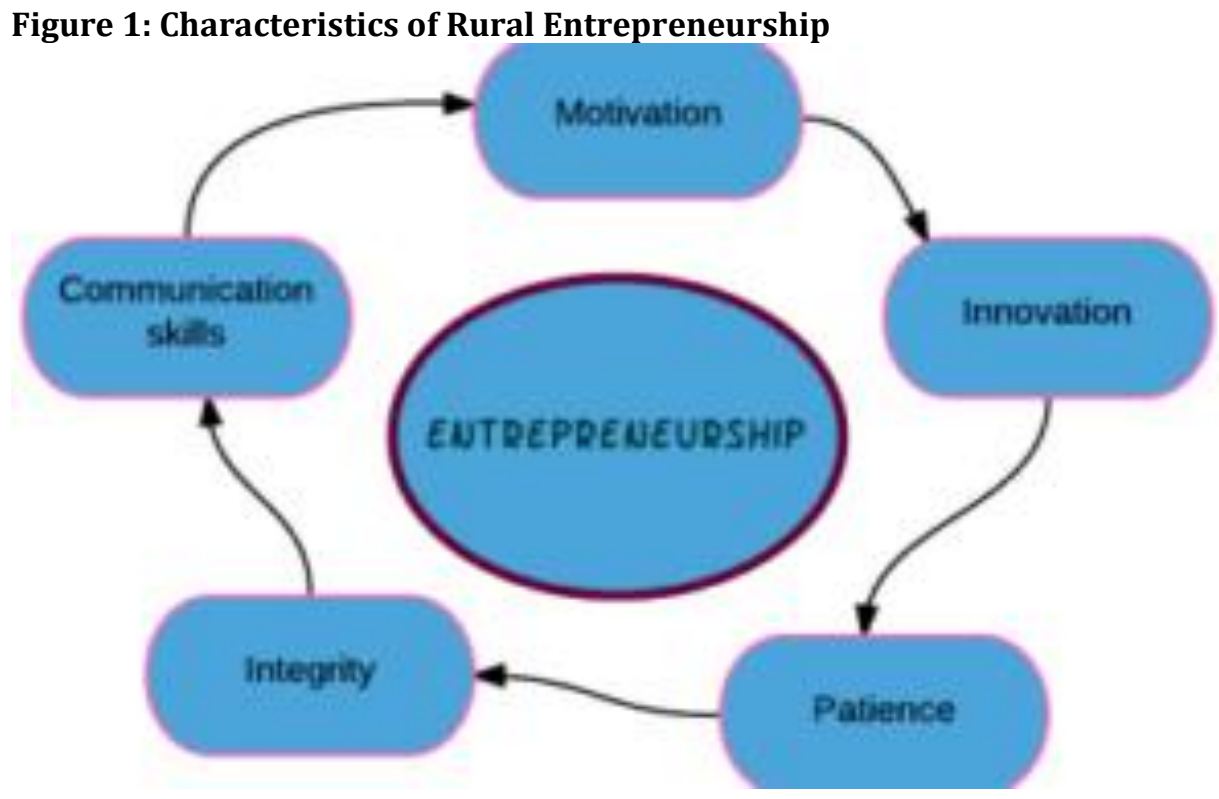

Source: (Petrin, 1992)

Types of Rural Entrepreneurship: Below are four types of rural entrepreneurship, and these are:

- Individual Entrepreneurship: It is single proprietorship of an enterprise in a rural community by an individual for poverty alleviation, profit-making, job creation and wealth accumulation;

- Group Entrepreneurship: This simply involves every enterprise which is formed through public, private partnerships in the rural community to create jobs and alleviate poverty;

- Cluster Entrepreneurship: This encompasses every networking amongst Non-Governmental Organisations, Community Based Organisations and Self Help Groups which form an enterprise for poverty alleviation and job creation; and

- Cooperative Entrepreneurship: This is an autonomous association of rural inhabitants who voluntarily unite for the collective objective of alleviating poverty by creating jobs (Casson, 2003). 
The National Development Plan and Rural Entrepreneurial Development Nexus: StatsSA (2016) notes that, the fraction of South Africans living in rural areas has decreased by an average of $10 \%$ since 1994 , and an average of $60 \%$ of this population lives in urban areas. A forecast from the global movements indicates that rural to urban migration is anticipated to increase by 2030 , with an average of $70 \%$ of the population moving to the urban areas in South Africa (StatsSA, 2016). The impasse of rural-urban migration has witnessed the growth of population in urban areas which are presently succumbing to service delivery demands from the public, as evident in the recurring service delivery protests. The Bureau for Agricultural Policy (BFAP) (2011) denotes that, rural-urban migration and its effects inter alia can only be addressed through a holistic approach that will witness the flow of labour from urban areas back to the rural areas, through the implementation of sustainable entrepreneurial activities. BFAP (2011) further explains that, mainstream rural communities are sustained by farming although rural growth is being gradually allied to enterprise development, which includes other non-farming undertakings. Hence, one of the main objectives of the NDP is to integrate the country's rural areas through infrastructural development, job creation and poverty alleviation as sustained by the dynamic forces of entrepreneurship (Department of the Presidency, 2015).

Chapter 6 of the NDP advocates for an integrated and inclusive rural economy through the creation of 643000 direct jobs and 326000 indirect jobs in the agriculture and allied enterprise sectors by 2030 (Hendriks, 2013). Thus, for the NDP to realize these goals in integrating an inclusive rural economy, it should stimulate local entrepreneurial talent in creating jobs and adding economic value to the rural communities. Essentially, Casson (2003) upholds that in accelerating economic development in rural areas, it is obligatory to increase the supply of entrepreneurs, thus building up the critical mass of entrepreneurs. This is against the background that Tyson, Petrin and Rogers (1994) confirm that communities that actively promote rural entrepreneurial development evidently demonstrate high growth rates and advanced levels of economic development. To this end, therefore, entrepreneurship has to be considered as a prime mover in rural economic development in South Africa since an entrepreneurial economy significantly differs from a nonentrepreneurial one, by the economic vigour of its inhabitants (The Department of the Presidency, 2009).

Thus, the Department of the Presidency (2015) posits that, entrepreneurial orientation to rural development should actually be based on stimulating local entrepreneurial talent and nurturing the subsequent growth of indigenous companies. This can only be sustained through outspreading entrepreneurship skills development and offering technical support to the rural entrepreneurs in capacitating and enabling them to achieve the mandate of the NDP. This will ensure integrated and inclusive rural areas in 2030, in which inhabitants will be economically dynamic, through inclusive rural development which facilitates poverty alleviation, wealth creation and sustainable growth (Hendriks, 2013).

\section{Theoretical Perspectives on Entrepreneurial Development}

Knight's Theory: Knight's theory $(1921 ; 1985)$ outlines uncertainty and risk as the basic building blocks in outlining what entrepreneurship is. McClelland (1961) maintains that, Knight's theory describes the most imperative physiognomies of the rural community by introducing uncertainty. Knight (1921/1985) discusses that if uncertainty is introduced into the economy; the execution of activities is secondary, since the primary factor is deciding what to do and how to do it, through entrepreneurial strategies. Wilken (1979) supports Knight's theory by confirming that commodities are primarily manufactured for the market not for the satisfaction of the producer's wants, hence manufacturing is done on a prediction basis of the market demand. Simply put, it is the sole responsibility of the manufacturer to project on the market demands and carry the risk of whether the commodities will be assimilated into the market. Young and Sexton (1997) argue that projecting over production is concerted upon a contracted portion of the producers whose aim is to enable a new economic functionary based on market demand. According to the Knight theory, the purpose of the rural entrepreneur is to project based on the market demand, carry the risk of loss and ultimately gain profit and forbear the risk of losing (Knight, 1921; 1985). This paper supports the Knight theory and its causal connection to the NDP's objectives of achieving an all-inclusive rural economy whose inhabitants are self-sufficient in taking risks in uncertain economies for sustainable entrepreneurial activities. 
Schumpeterian Theory: Byrd (1987) notes that entrepreneurship is a broad concept incorporating an extensive range of activities, from the Schumpeterian model of innovation to simple job creation for wealth creation. Schumpeter (1996) defines an entrepreneur as the director of manufacturing and a catalyst of change termed "creative destruction". Therefore, the Schumpeterian entrepreneur is an innovator who compels economic growth through knowledge and competition (Schumpeter, 1934). For Schumpeter (1934), the entrepreneur's role is to rearrange available resources by breaking prevailing symmetries and injecting entrepreneurial innovations through the process of "creative destruction". Schumpeter (1996), guided by the Schumpeterian theory, affirms that there is necessity entrepreneurship and opportunity entrepreneurship. The distinction between the two is that necessity entrepreneurship is driven by the absence of employment whilst opportunity entrepreneurship is driven by the active choice to own an enterprise based on opportunity and innovation (Schumpeter, 1996). Robeyns (2005) argue that necessity entrepreneurship is directly linked to poverty and does not create wealth since it is only for consumption. In contrast, opportunity entrepreneurship has long-term effects of economic growth since it involves creating innovative opportunities based on available resources. Resultantly, Audretsch (2007) defines entrepreneurship as the process of being innovative and developing an opportunity to create value without regard to either resources or the location of the entrepreneur. The Schumpeterian theory assumes that, the aim of rural entrepreneurship mechanisms is to support the ability of rural communities in embarking on pragmatic and innovative long-term approaches for economic development. In achieving the objectives of the NDP by 2030, the rural entrepreneur should not be deterred by geographical location or availability of resources. This is against the background of the Schumpeterian model which advocates for opportunity entrepreneurship in developing nations because it is driven by a high level of reactiveness to available opportunities in the existence of innovation and regardless of geographic location (Schumpeter, 1996).

Capability Approach: This paper supports that the NDP of 2012 is grounded in the Capability Approach, which accentuates on the autonomy of humans to have social adoptions and select what is of significance to them. This is against the background of the Capability Approach being the foundation of contemporary approaches of assessing human development, such as the Human Development Index (HDI) (UNDP, 2010). The HDI measures growth from the aspect of longevity from birth, adult literacy in terms of schooling and standard of living on per capita income basis. The Capability Approach advanced from Amartya Sen's reproach of dependence in welfare economics as the indicator of wealth (Sen, 2000). Sen (1985) defines capabilities in reference to a person's competencies in achieving a given operative which is valuable in making up a person's development.

Alkire (2005) maintains that human development requires that people not be passive recipients in their lives but that they should be proactive in realizing their goals. Hence, the Capabilities Approach provides a valuable point of departure in formalising the role of entrepreneurship in human development for rural inhabitants (Robeyns, 2005). This indicates that, entrepreneurship is not just a part of economic development, but a critical foundation of long-term economic development (Byrd, 1987). Rural entrepreneurship is, therefore, not only shaped by spatial features but also serves to transform the socioeconomic development systems for rural communities. The graphical illustration below shows the close link between capabilities, opportunities and entrepreneurship on rural economic development. The diagram also reveals how the impact of effective governance and proactive citizenry can drive development in a socially cohesive rural environment.

Figure 2: Good governance \& Rural Economic Development

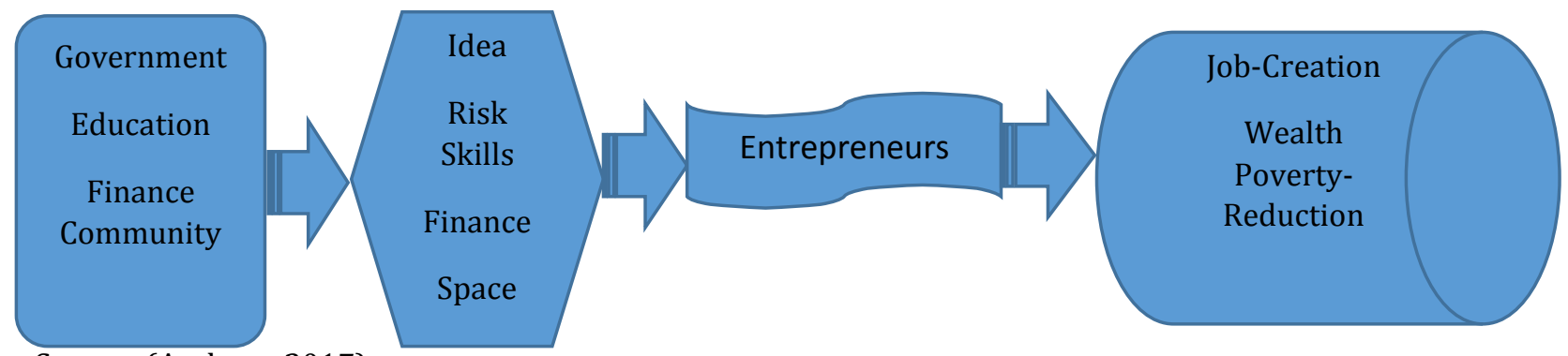

Source: (Authors, 2017) 


\section{Methodology}

The paper aims to assess the economic implications on National Development Plan 2012-2030 as an entrepreneurial mechanism for stimulating rural economic development in South Africa. It applied a qualitative research technique which has roots in the interpretive paradigm. This was achieved through various primary and secondary sources such as NDP Policy 2012-2030, National Planning Commission 20112012 reports, Global Entrepreneurship Monitoring (GEM) 2014, published and peer reviewed articles on rural economic development and entrepreneurship to collect data. This qualitative research method, as Denzin and Lincoln (2000) observe, is facing acceptance challenges due to academic and disciplinary resistance, although Neuman (1997) refutes the claims and credits the qualitative approach as a suitable technique for exploring data.

The paper formulated its themes from the following research questions: What is the nature of rural entrepreneurship in South Africa? Is the NDP succeeding in promoting rural economic development? What are the challenges facing NDP so far towards stimulating rural economic development? What other innovative solutions can be offered to the South African government to accelerate the implementation of NDP? Data collected from documents was analyzed qualitatively using thematic content analysis drawn from the research questions of this paper. Babbie (2001) supports thematic content analysis as essentially appropriate for arranging raw data into a standardized format to provide meaning. Ryan and Bernard (2000) endorse thematic content analysis as a fundamental technique for analysis and providing judgments based on the raw data collected by the researcher.

\section{Results}

The need to improve skills among rural entrepreneurs: The successful implementation of the National Development Plan in South Africa rests on the availability of skills to stimulate change. Literature from South Africa has shown that, marked improvements have been made in some sectors to conduct skills development programs. However, the majority of rural people still do not have the adequate skills to unlock the potential of entrepreneurship programs to improve their livelihoods. A study conducted by the Department of Trade and Industry in (2008) concurs with the findings; it endorses that skills shortage and limited entrepreneurship capacity constrain employment growth and decelerates the National Development Plan from championing rural economic development. There is a need for the government of South Africa to promote vocational education among young entrepreneurs since they carry the vision for advancing the economy of the country.

The need to unlock youth potential: The National Development Plan in South Africa was proposed with the aim of unlocking economic opportunities for the many jobless youths in the country. However, such youth appear to lack entrepreneurial minds or capacity to generate their own businesses, which is a set-back to NDP. A research conducted by the Global Entrepreneurship Monitor (GEM) (2014) corresponds with the above-mentioned findings when it indicates that for a developing nation like South Africa, the rate of entrepreneurship is relatively low in contrast to other Sub-Saharan countries. This is also contrary to what Lindiwe Zulu, the Minister of Small Business Development in South Africa, perceives when she projects South Africa as a prospective hub of entrepreneurship for the nation's job-seekers. A report by Stats SA (2014) further reveals lack of entrepreneurship among the economically active people, particularly women, who seem to be trapped in the patriarchal cloud that restricts women involvement in business. The report shows a reduction in young entrepreneurs from 609000 in 2009 to 543000 in 2014. Based on these assertions and statistics, there is a greater need for South African youth to embrace the NDP as it aims to re-invigorate local economies and improve rural livelihoods in particular. The challenge, however, remains for the rural youth to change their mindset and become employers rather employees. Such radical thinking can lead to improved rural economic development, as orchestrated in the NDP.

The need to revoke government bureaucracy: In South Africa, the National Development Plan was ushered in as a universal economic blueprint to benefit various sectors of life. However, successful implementation and sustainability of this policy depends on government bureaucracy and its ability to release funds to support entrepreneurial development. Global Entrepreneurship Monitor (2014) and the WEF 2014/15 Global Competitiveness Report support such findings when they reveal that, top down government bureaucracy acts 
as a barrier to the growth and expansion of entrepreneurship in South Africa. Many potential entrepreneurs are frustrated by the delays in securing business licenses. The drastic red tape on its own is a barrier which the government needs to address in order to achieve the objectives of NDP. The apparent lack of proper coordinating structures in government policy may discourage entrepreneurship and small businesses. The Department of Trade and Industry (DTI) (2005) laments the lack of inter-departmental cooperation which often weakens government efforts to promote entrepreneurship through proper planning and cooperation. Conflicts which often emerge in government entities are hindrances to the development of SMMEs. Critical scholarship condemns this lack of unity which culminates into duplication of programs to support the NDP.

The need to increase access to markets\& credit facilities: Rural economic development in South Africa is mainly being orchestrated by cooperatives (women, agricultural, youth cooperatives) and SMMEs. However, due to low levels of education and technological inabilities, many rural entrepreneurs who rely on agricultural cooperatives, as entrepreneurial mechanisms for poverty reduction, often face challenges when locating appropriate markets for exporting their produce. Their inability to identify potential markets due to poor information dissemination is a hindrance to achieving the aims and objectives of the NDP. Rural economies in the NDP have been projected to be viable through government intervention with economic development programs; therefore, failure to have equitable access to markets can be a stumbling block to poverty alleviation and rural economic development. Notwithstanding their lack of collateral security to secure funding from credit institutions, rural entrepreneurs lack mentorship on how they can align the NDP to entrepreneurial development. These views were contrasted by Watson and Netswera (2009) in their study when they regarded urban entrepreneurs as better positioned for access to credit institutions and entrepreneurial education than their rural counterparts. Based on these assertions, rural economic development through other NDP can be a success when rural entrepreneurs in South Africa are assisted by relevant stakeholders to identify markets and given access to credit facilities to finance development projects.

The need to promote research culture and innovation: The National Development Plan in South Africa is hinged on the adoption of various latest technologies (telecommunications, biotechnology, microprocessors) introduced by globalization in the $21^{\text {st }}$ century. These technologies are fundamental in advancing science and research, entrepreneurship as well as efficiency in the functioning of public sector. Nevertheless, since the inception of NDP in 2011, there has been a limited research and development capacity to advance entrepreneurship in South Africa. The economically active population which is expected to be the driver of entrepreneurship and small businesses development seems to be trapped in the technological inability dilemma. Unemployment in South Africa is escalating due to limited ability to embrace research on the use of technology, and this result in huge skills gap and declining rural economic development. Lack of innovativeness was supported by empirical findings from Booysen's (2011) study which shows that South Africa's SMMEs and entrepreneurs are less innovative compared to developed countries. To bridge this challenge and accelerate rural economic development, the GEM report (2014) offers innovative suggestions to the government to incentivize research and development as pre-requisites to enhance economic development. Such an initiative can be used to foster innovation, at the same time attracting foreign direct investment and creating linkages between domestic and local firms towards improve rural economic development.

Promoting entrepreneurial education and culture among rural citizens: Rural economic development, through the National Development Plan in South Africa, is being constrained by lack of entrepreneurial education and culture among the majority of rural populations. These findings augur well with a recent study conducted by the GEM (2016) on the growth of entrepreneurship. The study shows various reasons that hamper entrepreneurial growth which include lack of research, culture and social norms. In terms of entrepreneurial education, the study revealed that South Africa is at $42 \%$, which is far below the expected standard envisioned by the NDP. Government efforts in promoting SME sector can be perceived as a direct move to strengthen entrepreneurship; however, various experts have criticized government policies as detrimental to the effective implementation of NDP to promote rural economic development. The GEM report indicates further that the rate of entrepreneurship in South Arica has actually declined as compared to 2010 whereby entrepreneurs account for $50-60 \%$ between ages of 24 and 44 . A critical assessment on these results made Chetty (2016) to provide suggestions to government to provide entrepreneurial education starting from primary school level up to tertiary institutions to model Denmark and Israel. Fostering the culture of 
entrepreneurship can help future entrepreneurs to have their minds directed towards employment-creation and self-sustainability.

Curbing rampant corruption in rural economic development: It seems as if corruption is now acceptable in every development program in South Africa. Critics argue that corruption is the cancer which has ripped apart many private and, most importantly, public institutions due to the loss of moral code among upper echelons of government. The same cancer has been spreading, thereby creating devastating consequences on government efforts to generate employment and improve the lives of people in rural areas of South Africa. Through an extensive documentary review and analyses of other empirical studies, we argue that corruption has a massive impact on the economy and rural entrepreneurship. In many circumstances, money directed towards development initiatives is either abused or diverted to other programs, which results in the ineffectiveness of the NDP which seeks to reduce poverty in most impoverished communities of South Africa. The Transparency International Corruption Perceptions Index shows that South Africa is ranked 69 th among 176 countries. The Corruption watch 2016 placed South Africa at $64^{\text {th }}$ out of 176, which portrays a slight reduction in corruption levels.

These findings indicate low levels at which South Africa is, in terms of promoting rural entrepreneurship. Even though it has become a common norm to blame every failure on the effects of apartheid, Plaut (2012) affirms that poor mismanagement has been a root cause for failed economic policies. Across the socioeconomic and political divide in South Africa, corruption is difficult to control although some experts argue that anti-corruption measures can be put into place to safeguard public funds. Rural economic development, as an NDP imperative, can be successful when there is will power and change of moral codes among accounting authorities who often abuse state funds for personal gain.

\section{Conclusion and Recommendations}

The paper attempts to assess the successes and failures of the National Development Plan so far, a South African government economic blueprint adopted in 2012 aimed to be fully functional by 2030 . The economic framework was designed to stimulate rural economic development among other important things in the economy of the country. Evidence from the paper has reflected that NDP, as an entrepreneurial mechanism for job creation and rural economic development, is still facing numerous challenges emanating from underfinancing, lack of entrepreneurial education and research culture, negative attitudes of the people, corruption, red tape and lack of innovation. These challenges are rampant among rural entrepreneurs in many provinces of South Africa. The NPC (2011) acknowledges these challenges and seeks to propose the way forward on how rural economic development can be channeled to ensure improved livelihoods of people of South Africa. Based on the results of the paper, for NDP to be continuously coordinated as an economic initiative, financing of rural projects such as small businesses, cooperatives and other rural development projects needs to be a government top priority.

There is a need to integrate entrepreneurial education in the academic curriculums in schools so that it becomes a core and not an elective subject, which is fundamental to the young and upcoming entrepreneurs. Entrepreneurship culture should be fostered through various entrepreneurial and capacity building workshops, training and development through vocational schools. The government of South Africa, through its designated departments (Department of Trade and Industry, Economic Development, Higher Education and Training), should place emphasis on the use of research and innovation hubs that promote individual or group research on the best ways to implement the NDP. Preconceived and ill-timed development offered by government toward rural entrepreneurs is often not grounded on the needs or what the rural entrepreneurs need to improve their lives. To this end, therefore, outsourcing of academics or other independent research institutes can assist in proposing innovative ways of improving NDP implementation towards rural economic development. Partnerships with BRICS countries such as India or Brazil can help foster knowledge-sharing since entrepreneurship in these countries contributes much to job creation and improvements in the growth domestic product. 


\section{References}

Alkire, S. (2005). Capability and functioning: definition and justification. Human Development and Capability Association Briefing Note. From: http://www.masterhdfs.org/masterHDFS/wpcontent/uploads/2014/05/Alkire-Capability-Functioning-Briefing-Note.pdf. Accessed 15 April 2017.

Accelerated and Shared Growth Initiative for South Africa (ASGISA) Annual Report. (2006). From: http://www.thepresidency.gov.za/docs/ asgisa2006.pdf, Accessed 04 April 2017.

Audretsch, D. B. (2007). Entrepreneurship capital and economic growth. Oxford Review of Economic Policy, 23, 63-78.

Babbie, E. (2001). The practice of social research (9th ed.). Belmont: Wadsworth.

Booysens, I. (2011). Are Small, Medium, and Micro-Sized Enterprises Engines of Innovation? The Reality in South Africa. Science and Public Policy, 38(1), 67-78.

Bureau for Agricultural Policy (BFAP). (2011). The contribution of the agro-industrial complex to employment in South Africa. Unpublished report prepared for the National Planning Commission.

Byrd, W. A. (1987). 'Entrepreneurship, capital and ownership'. Washington, D.C. Mimeo: The World Bank.

Chetty, C. in Lebohang, T. (2016). Rebels with a cause: The state of SA's youth on frustration and the fight for economic freedom. From: http://www.smesouthafrica.co.za/16578/Rebels-with-a-cause-The-stateof-youth-2016. Accessed 15-04-2017.

Casson, M. (2003). The Entrepreneur: An Economic Theory (2nd Ed.). Chelterham: Edward Elgar.

Corruption Watch. (2016). Bua Mzansi Annual Report, Vol 1(1). From: https://www.corruptionwatch.org.za/wp-content/uploads/2017/02/Corruption-Watch-AnnualReport-27-02-2017-Low-Res-Version.pdf. Accessed 04-04-2017.

Denzin, N. K. \& Lincoln, Y. S. (2000). Introduction: The discipline and practice of qualitative research. In Norman K. Denzin \& Yvonna S. Lincoln (Eds.), Handbook of qualitative research (2nd ed., pp.1-28). Thousand Oaks: Sage.

Global Entrepreneurship Monitor (GEM). (2014). The crossroads - a goldmine or a time bomb? Cape Town: Global Entrepreneurship Monitor.

Global Entrepreneurship Monitor (GEM). (2016). From GEM: http://www.gemconsortium.org. Accessed 03 April 2017.

Hendriks, S. (2013). South Africa's NDP and New Growth Path: Reflections on policy contradictions and implications on food security. Agrekon, 52(3), 1-17.

Knight, F. H. (1921/1985). Risk, Uncertainty, and Profit. Chicago: University of Chicago Press.

McClelland, D. C. (1961). The Achieving Society. Princeton, New Jersey: Van Nostrand.

National Planning Commission (NPC). (2011). Diagnostic overview. Pretoria: National Planning Commission, Office of the Presidency.

National Planning Commission (NPC). (2012). National Development Plan. Pretoria: National Planning Commission, Office of the Presidency.

Neuman, W. L. (1997). Social research methods, qualitative and quantitative approaches (3rd ed.). Boston: Allyn and Bacon.

Petrin, T. (1992). 'Is Entrepreneurship Possible in Public Enterprises'?' in J. Prokopenko and I. Pavlin (eds.), Entrepreneurship Development in Public Enterprises, ILO, Geneva and International Centre for Public Enterprises in Developing Countries.

Plaut, M. (2012). Crime, corruption and political connections. Sunday Times Review, p. 5.

Robeyns, I. (2005). The capabilities approach: a theoretical survey. Journal of Human Development, 6(1), 93114.

Ryan, G. W. \& Bernard, H. R. (2000). Data management and analysis methods. In Norman K. Denzin \& Yvonna S. Lincoln (Eds.), Handbook of qualitative research (pp.769-802). Thousand Oaks: Sage.

Schumpeter, J. A. (1934). The Theory of Economic Development. Harvard University. Cambridge M.A.

Schumpeter, J. A. (1996). The theory of Economic Development. London. Transaction Publishers.

Sen, A. (1985). Commodities and Capabilities. North-Holland, Amsterdam.

Sen, A. (2000). Development as Freedom. Anchor Books, New York.

South African Government Information (2012). Social development. Available from: www.info.gov.za/aboutsa/socialdev.htm\#social-assistance. Accessed on 23 March 2017.

South Africa, Department of Trade and Industry. (2005). Integrated Strategy on the Promotion of Entrepreneurship and Small Enterprises. Pretoria. 
South Africa, Department of Trade and Industry. (2008). Annual review of small business in South Africa 2005-2007. Pretoria: Department of Trade and Industry.

Stats SA (Statistics South Africa). (2012b). In-depth analysis of the General Household Survey data. GHS Series 4: Food security and agriculture 2002-2011. Report No. 03-18-03. Pretoria. Statistics SA.

StatsSA (Statistics South Africa). (2016). General Household Survey. Pretoria: Statistics South Africa.

South Africa. The Department of the Presidency. (2009). National Income Dynamics Study. Sherino Printers. National Planning Commission.

South Africa. The Department of the Presidency. (2015). National Development Plan 2030, Our Future make it works. Sherino Printers. National Planning Commission.

Tyson, L. T., Petrin, T. \& Rogers, H. (1994). Promoting Entrepreneurship in Central and Eastern Europe. Small Business Economics, 6, 1-20.

UNDP (2010). The real wealth of nations: Pathways to human development. Human Development Report 2010. New York, UNDP.

Watson, L. \& Netswera, G. (2009). Support for Rural Small Businesses in Limpopo Province, South Africa. Development Southern Africa, 3, 225-239.

Wilken, P. H. (1979). Entrepreneurship. A Comparative and Historical Study. Norwood, New Jersey: Ablex Publishing Corporation.

Young, J. E. \& Sexton, D. L. (1997). Entrepreneurial Learning: A Conceptual Framework. Journal of Enterprising Culture, 5(3), 223-248. 